\title{
ANALYSIS ON THE VULNERABILITY OF THE MIDDLE-SCHOOL POPULATION IN VASLUI COUNTY
}

\author{
Dan BADEA ${ }^{1 *}$, Sorin CIOLC $\breve{A}^{1}$, Grigore GHEORGHE ${ }^{1}$ \\ ${ }^{1}$ National University of Physical Education and Sport, Faculty of Physical Education and Sport, \\ Bucharest, Romania \\ *Corresponding author: dan_badea14@yahoo.com
}

https://doi.org/10.35189/dpeskj.2020.59.4.3

\begin{abstract}
The present research is part of the project called "Sustainable social and educational integration through sports activities", which is focused on increasing both the school attendance rate for students in lower secondary education and the ISCED 3 transit rate. Vaslui county has a wide range of vulnerabilities affecting this segment of the school population. Our study aims to highlight the structure of these vulnerabilities, which are divided into 8 categories as follows: Roma students, students with one or both parents working abroad, remigrating students, students from disorganised or single-parent families, students from child protection institutions, students whose parents are immigrants/refugees in Romania, students with special educational needs, students at risk of early school dropout. This applied research was carried out over a period of 3 months. The participating subjects are students enrolled in two middle schools that have an ISCED below 50\%; their total number is 190, of whom 105 boys and 85 girls. The research methods used are: scientific documentation, survey, mathematical and statistical method, graphical method. The results of the research are reflected in the identification of vulnerability structures for students in lower secondary education from Vaslui county. The research actually makes an X-ray of the social problems faced by middle-school students in rural areas.
\end{abstract}

Keywords: students, lower secondary education, vulnerability, structure.

\section{Introduction}

In modern knowledge and information societies where schooling and lifelong learning are of critical importance, dropout from school is a severe problem (Wilson et al., 2011).

Romania has one of the highest percentages of early school dropout among European countries. Early school dropout is a phenomenon that directly leads to social exclusion and has an impact on both the individual and the entire community.

Social exclusion is associated with adverse effects for both mental and physical health; for example, ostracism is a ubiquitous phenomenon across the lifespan that threatens the fundamental human need to belong to a group (Pollatos et al., 2015). Being ostracised causes social pain, loneliness, anxiety and sadness (Hawkley et al., 2011). On the other hand, the need to belong is a basic, powerful and pervasive motivation in the life of an individual (Baumeister \& Leary, 1995).

Early school dropout is directly related not only to social exclusion, but also to unemployment, poverty and poor health. Material deprivation and poverty are perceived as predominant in most communities, especially in rural areas with a Roma population exceeding $30 \%$ to $40 \%$, which are located over $20 \mathrm{~km}$ away from a city that offers more job opportunities. The job offer is usually very limited in these areas, which is why, in the vast majority of families, at least one or even both parents are unemployed. Their only income is from social assistance, allowance and seasonal, informal activities. (Ilisei, 2016) 
In this context, the Government of Romania has declared that reducing the phenomenon of early school dropout and improving the motivation and professionalism of teachers and educational experts are priorities at national level.

In lower secondary education, the number of students is constantly decreasing by about 12,000 children annually. This decline is caused by the dynamics of the population with 'theoretical schooling age for this level of education, but also by the annual school failure resulting from the phenomenon of early school dropout. At the same time, the statistically lower level of education among the Roma population compared to the non-Roma population maintains a vicious circle of poverty and social exclusion, parents do not find jobs because of their lack of qualification, and this makes it difficult for them to earn income that would allow them to send their children to school (Ilisei, 2016). The conclusions of a study conducted in the UK suggest that the experience of racism, the impact of cultural dissonance as well as low teacher expectations may all be contributory factors affecting Gypsy students' educational involvement and achievement (Derrington \& Kendall, 2008). According to Derrington (2007), students who rely on maladaptive coping strategies to deal with psychosocial stress associated with cultural dissonance and social exclusion tend to drop out of school early.

As regards the gender percentage of children attending school, there are no significant differences between boys and girls. However, these differences appear at ages that exceed the theoretical schooling age for lower secondary education and highlight that boys' participation is better (Horga et al., 2017). Overall, the media portrayal contributes to maintaining gender stereotypes 'by impairing boys' and strengthening girls' performance in female connoted domains and by prompting boys to align their learning goals to the gender connotation of the domain" (Latsch \& Hannover, 2014).

In terms of residence environment, better school attendance is noted for children in urban areas compared to those in rural areas. It is also observed that the percentage of children enrolled in lower secondary education in urban areas exceeds $100 \%$, which reflects a temporary transfer of middle school-aged students from rural to urban areas in order to complete this level of education.

Alterable school characteristics such as discipline practices, resources, school size and student-teacher ratio influence students' educational decisions (Tyler \& Lofstrom, 2009), as do characteristics outside of the school's direct influence such as its location and the make-up of the student body (Lofstrom, 2007). Moreover, caring teachers who have high expectations for the success of all students are associated with lower dropout rates (Christenson et al., 2001).

Hence the need to develop programmes and policies aimed at supporting children to participate in education in rural areas, but also to invest in human resources working with these children to keep them in the education system over an extended period of time. Tonts (2005) states that sport is often regarded as an important part of life, contributing to community identity, sense of place, social interaction and good health.

A negative trend is observed in the percentage of students enrolled in middle school, which reflects a very large number of children in this age group that are outside of the education system. In this respect, the family environment is particularly important for the participation of children and youth in education. A rural school principal summarises the 
cases with the highest risk as follows: In economic terms, many children are from singleparent families, have a parent who is in prison, or have a parent who is unemployed, and this can be seen in their school behaviour. Some of them are raised by grandparents. There are also children from migrating families (school principal, rural areas). The absence of one parent or both parents can affect the school performance of children/young people not only by the lack of material resources needed to participate in education, but also by the fact that children and youth often do not benefit from emotional, educational and care support (Ilisei, 2016).

Several scientists have claimed that school absenteeism can be best understood within the context of school engagement, such that there is a continuum of school engagement ranging from full engagement to school dropout, with absenteeism located somewhere along that continuum. The social mechanisms behind this school engagement continuum are complex, but nevertheless involve school absenteeism as a predictor of school dropout. (Tanner-Smith \& Wilson, 2013)

Regarding the gender parity index, it shows that there are no significant differences between girls and boys. The values are close and, in both cases, their constant decrease up to around $90 \%$ can be noticed. (Horga et al., 2017)

The highest proportion of out-of-school children is generally found at the ages of 13 and 14 years, which may be due to the increased rate of school dropout by the end of this level of education.

In lower secondary education, the rate of early school dropout has a relatively constant value of about $12 \%$ but, in recent years, it has been slightly increasing especially in rural areas, reaching up to $15 \%$, and school failure has exceeded $18 \%$. In other words, a little over 1 in 10 students in urban areas and almost 2 in 10 students in rural areas drop out of middle school. Hence the need for significant improvement actions in rural lower secondary education to reduce the rate of early school dropout. In terms of gender distribution, the difference highlights that more boys than girls drop out of school during lower secondary education. If we take into account the percentage of repeaters in the final year of middle school, in which case also boys record higher values, early school dropout throughout lower secondary education is significantly higher for boys compared to girls.

The rate of early school dropout is caused by several vulnerabilities. According to Merriam-Webster Dictionary (2020), the concept of vulnerable means "capable of being easily hurt or injured". Those who are attributed the characteristic of "vulnerable" are weak, exposed and without protection. The concept of vulnerable point indicates the weak side, the soft spot, the sore point of someone.

At school level, we identified the following 8 categories of vulnerabilities: Roma students, students with one or both parents working abroad, re-migrating students, students from disorganised or single-parent families, students from child protection institutions, students whose parents are immigrants/refugees in Romania, students with special educational needs, students at risk of early school dropout.

Students with special educational needs (SEN) fall into one of the following situations of vulnerability: children classified into a degree of disability, who receive school/professional guidance from the Council for School and Professional Guidance (COSP), having both disabilities and SEN; children classified into a degree of disability, who do not receive 
school/ professional guidance, having both disabilities and SEN, but for whom parents/legal guardians do not require school guidance; children classified into the category of severe disabilities, for whom educational measures are mainly aimed at the full development of their human potential, mental and physical abilities, personality, talent and creativity; children and youth who are not classified into a degree of disability, who receive school/professional guidance from the COSP and are either children that have both disabilities and SEN, but for whom parents do not require/ refuse classification into a degree of disability, or children only with SEN; children who are not classified into a degree of disability, who do not receive school/professional guidance and have both disabilities and SEN, but for whom parents/legal guardians do not require either school guidance or classification into a degree of disability; other children at risk as regards the development of personal skills, with learning, developmental or school adaptation difficulties, who are at some point in a school failure situation or at risk of school dropout, who are identified as such by specialised staff (teachers, school counsellors, speech therapy teachers, etc.), but who are not yet recognised with SEN and/or disabilities, and therefore do not benefit from specialised support.

The school environment offers promise as a means of extending the achievement of effective interventions for mental health to underserviced populations (Mifsud \& Rapee, 2005).

This research is part of the project called "Sustainable social and educational integration through sports activities", which is focused on increasing both the school attendance rate for students in lower secondary education and the ISCED 3 transit rate.

\section{Research purpose}

Vaslui county has the highest level of poverty in our country, being one of the counties with a high degree of early middle-school dropout and therefore having a wide range of vulnerabilities for this segment of the school population. Our research aims to highlight the structure of vulnerabilities of the middle-school population in this county.

\section{Methodology}

This applied research was carried out over a period of 3 months, in the 2019-2020 school year. The participating subjects are students enrolled in two schools, and their total number is 190, of whom 105 boys and 85 girls. Both schools ("Cezar Botez" Middle School in Fâstâci and Gârceni + Racova Middle School) are from rural areas, have an ISCED below 50\% and record a number of 2,397 absences in the 2019-2020 school year.

The research methods used are: scientific documentation, survey, mathematical and statistical method, graphical method.

Vulnerabilities targeted by this research are: the student is at risk of early school dropout for other reasons than those listed below such as belonging to a socially assisted family, cohabitation with other students exposed to the risk of early school dropout, other forms of poverty, etc.; the student belongs to Roma ethnicity; the student has one or both parents working abroad; the student has re-migrated and needs support for school and social reintegration after coming back from abroad; the student is from a disorganised or single- 
parent family; the student is from a child protection institution or benefits from another protection measure; the student belongs to a family of immigrants/refugees in Romania; the student is classified as a person with special educational needs; the student is classified as a disabled person.

In order to collect the data necessary to assign students to one or more categories of vulnerabilities, the parents of students involved in the research completed a declaration regarding the inclusion of their children into a vulnerable category and the avoidance of double funding. This declaration is presented below.

\section{DECLARATION ON BELONGING TO A VULNERABLE CATEGORY AND AVOIDING DOUBLE FUNDING}

The undersigned (family name, first name) residing in the locality , county , street

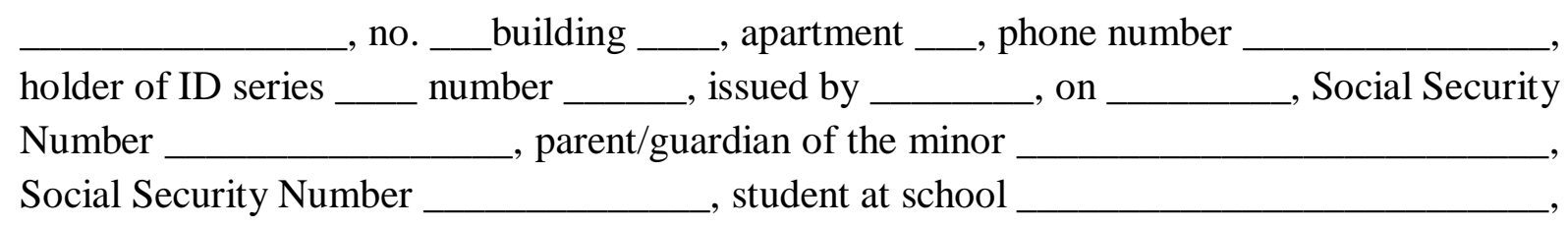
grade , in the locality

I declare on my own responsibility that the minor is not involved in projects (implementation or sustainability period) aimed at providing educational services that require the engagement of children at risk in integrated sports activities such as those provided by the National University of Physical Education and Sport in Bucharest within the "Sustainable social and educational integration through sports activities" project, code PNP001, as part of the "Local development, poverty reduction and increasing Roma inclusion" programme for 2014-2021. I also declare the following regarding the inclusion of the minor into one or more categories de vulnerabilities:

the minor is at risk of early school dropout;

the minor belongs to Roma ethnicity;

the minor has one or both parents working abroad;

$\square$ the minor has re-migrated and needs support for school and social reintegration after coming back from abroad;

the minor is from a disorganised or single-parent family;

the minor is from a child protection institution or benefits from another protection measure;

the minor belongs to a family of immigrants/refugees in Romania;

the minor is classified as a person with special educational needs;

the minor is classified as a disabled person.

I have acknowledged that my false statement leads to the following consequences:

- exclusion of the minor from the activities carried out within the project until the discovery of the false statement;

- legal responsibility for any possible prejudice caused to the National University of Physical Education and Sport in Bucharest.

Date 
Clear full name of the parent/legal guardian

Signature of the parent/legal guardian

\section{Results}

The data provided in the Declaration on belonging to a vulnerable category were processed and it was found that, in the two middle schools in Vaslui county, only four categories of vulnerabilities were highlighted, namely: students at risk of early school dropout for other reasons than those listed below such as belonging to a socially assisted family, cohabitation with other students exposed to the risk of early school dropout, other forms of poverty, etc.; students of Roma ethnicity; students with one or both parents working abroad; students from disorganised or single-parent family. The data processing has revealed the following results for lower secondary education:

Of the total number of 190 middle-school students, 85 are female (44.73\%) and 105 are male (55.26\%). Vulnerability with the highest percentage is represented by the segment of students at risk of early school dropout, namely 88 children, that is $46.31 \%$ of the total number of middle-school students. This result is in accordance with the data provided by INS (National Institute of Statistics) (2003-2016) on school dropout in rural areas, which represents $15 \%$, and school losses of $18.7 \%$. The second major vulnerability is represented by the Roma segment of the school population, over a quarter, namely 53 students, that is $27.89 \%$. The next vulnerability identified in the middle-school population is represented by the segment of students from disorganised or single-parent families, namely 27 students, that is $14.21 \%$. The lowest percentage among vulnerabilities is represented by the segment of students with one or both parents working abroad, namely 22 students, that is $11.57 \%$. Therefore, we notice that the structure of vulnerabilities among middle-school students is dominated by the risk of early school dropout. Regarding the structure of vulnerabilities by gender, a relative similarity can be observed as follows:

In girls, vulnerability with the highest percentage is represented by the segment of students at risk of early school dropout, namely 42 students, that is $49.41 \%$ of the total number of middle-school girl students. The second major vulnerability is represented by the Roma segment of the school population, namely 20 girl students, that is $23.52 \%$. The next vulnerability identified in the middle-school female population is represented by the segment of students from disorganised or single-parent families, namely 13 students, that is $15.29 \%$. The lowest percentage among vulnerabilities is represented by the segment of girl students with one or both parents working abroad, namely 10 students, that is $11.76 \%$.

In boys, vulnerability with the highest percentage is represented by the segment of students at risk of early school dropout, namely 46 students, that is $43.80 \%$ of the total number of middle-school boy students. The second major vulnerability is represented by the Roma segment of the school population, namely 33 students, that is $31.42 \%$. The next vulnerability identified in the middle-school male population is represented by the segment of students from disorganised or single-parent families, namely 14 students, that is $13.33 \%$. The lowest percentage among vulnerabilities is represented by the segment of boy students with one or both parents working abroad, namely 12 students, that is $11.42 \%$. 
The comparative analysis shows a higher percentage of vulnerability for the risk of early school dropout in girls than in boys. Instead, we notice a significant percentage of vulnerability for boy students belonging to Roma ethnicity. (Table 1)

Table 1. Overall results for the middle-school population

\begin{tabular}{|c|c|c|c|c|c|c|}
\hline \multirow[b]{2}{*}{ ROMA } & \multicolumn{2}{|c|}{ GIRLS - 85} & \multicolumn{2}{|c|}{ BOYS - 105} & \multicolumn{2}{|c|}{ TOTAL - 190} \\
\hline & 20 & $23.52 \%$ & 33 & $31.42 \%$ & 53 & $27.89 \%$ \\
\hline PMS & 10 & $11.76 \%$ & 12 & $11.42 \%$ & 22 & $11.57 \%$ \\
\hline FDM & 13 & $15.29 \%$ & 14 & $13.33 \%$ & 27 & $14.21 \%$ \\
\hline RPTS & 42 & $49.41 \%$ & 46 & $43.80 \%$ & 88 & $46.31 \%$ \\
\hline
\end{tabular}

Legend: Roma - the student belongs to Roma ethnicity; PMS - the student has one or both parents working abroad; FDM - the student is from a disorganised or single-parent family; RPTS - the student is at risk of early school dropout for other reasons than those listed below such as belonging to a socially-assisted family, cohabitation with other students exposed to the risk of early school dropout, other forms of poverty, etc.

For a complete picture of the vulnerability structure, we processed and interpreted the data for each middle-school grade.

Thus, for the 5th grade, the following results have been obtained:

Of the total number of 67 students in the 5th grade, 25 are female $(37.31 \%)$ and 42 are male $(62.68 \%)$. Vulnerability with the highest percentage is represented by the Roma segment of the school population, namely 24 students, that is $35.82 \%$ of the total number of students in the 5th grade. The second major vulnerability is represented by the segment of students at risk of early school dropout, namely 23 students, that is $34.32 \%$. The next vulnerability identified for the 5th grade is represented by the segment of students with one or both parents working abroad, namely 11 students, that is $16.41 \%$. The lowest percentage among vulnerabilities is represented by the segment of students from disorganised or singleparent families, namely 9 students, that is $13.43 \%$. Thus, we notice that the structure of vulnerabilities for the 5th grade is different from the overall structure of vulnerabilities in the middle-school population, in the sense that the main vulnerability is related to students belonging to Roma ethnicity. Regarding the structure of vulnerabilities by gender, the following significant differences can be observed:

In girls, vulnerability with the highest percentage is represented by the segment of students at risk of early school dropout. The second major vulnerability is represented by the Roma segment of the school population, over a quarter. The next two vulnerabilities identified for the female population in the 5th grade have equal percentages and are represented by the segment of students from disorganised or single-parent families and the segment of students with one or both parents working abroad.

In boys, vulnerability with the highest percentage is represented by the segment of students of Roma ethnicity, followed by vulnerability representing students at risk of early school dropout. The next vulnerability identified in boys is represented by the segment of students with one or both parents working abroad, and the lowest percentage among vulnerabilities is represented by the segment of students from disorganised or single-parent families.

The comparative analysis shows a higher percentage of vulnerabilities for the Roma ethnicity and the risk of early school dropout in boys than in girls. Instead, we notice more significant percentages for the other two vulnerabilities in girl students. (Table 2, Figure 1) 
Table 2. Overall results for the 5th grade

\begin{tabular}{lrrrrrr}
\hline & \multicolumn{2}{c}{ GIRLS -25} & \multicolumn{2}{c}{ BOYS - 42 } & \multicolumn{2}{c}{ TOTAL - 67 } \\
ROMA & 7 & $28 \%$ & 17 & $40.47 \%$ & 24 & $35.82 \%$ \\
PMS & 5 & $20 \%$ & 6 & $14.28 \%$ & 11 & $16.41 \%$ \\
FDM & 5 & $20 \%$ & 4 & $9.52 \%$ & 9 & $13.43 \%$ \\
RPTS & 8 & $32 \%$ & 15 & $35.71 \%$ & 23 & $34.32 \%$ \\
\hline
\end{tabular}

Legend: Roma - the student belongs to Roma ethnicity; PMS - the student has one or both parents working abroad; FDM - the student is from a disorganised or single-parent family; RPTS - the student is at risk of early school dropout for other reasons than those listed below such as belonging to a socially assisted family, cohabitation with other students exposed to the risk of early school dropout, other forms of poverty, etc.

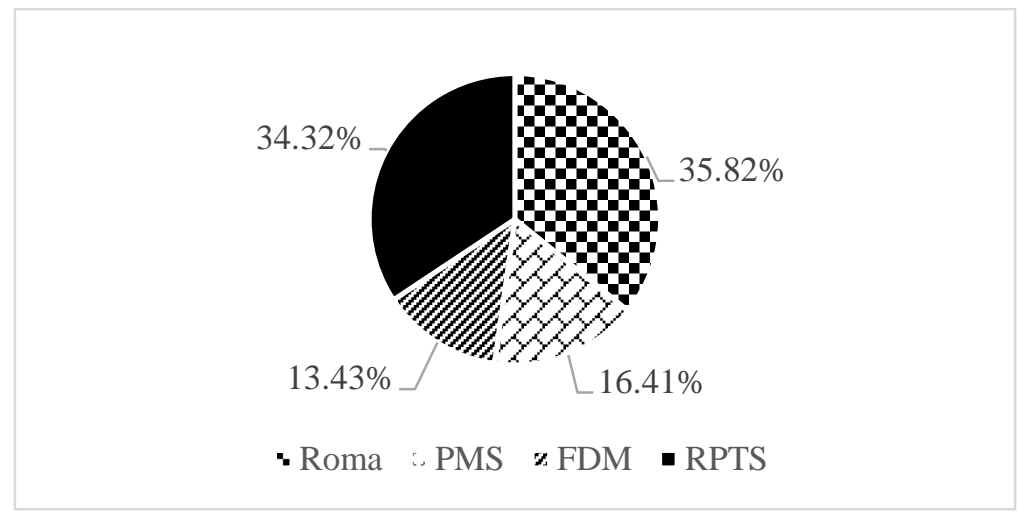

Figure 1. Structure of vulnerabilities - Overall results for the 5th grade

The processing and interpretation of data for the 6th grade show a number of 50 students at this level, of whom 21 are female (42\%) and 29 are male (58\%). Vulnerability with a major percentage is represented by the segment of students at risk of early school dropout, followed by a second important percentage of vulnerability, which is represented by the segment of Roma students. The next vulnerability identified in the middle-school population is represented by the segment of students from disorganised or single-parent families, and the lowest percentage among vulnerabilities is represented by the segment of students with one or both parents working abroad. Thus, we notice that the structure of vulnerabilities for the 6 th grade is dominated by the risk of early school dropout, namely 52\%. Regarding the structure of vulnerabilities by gender, the following major differences can be observed:

In girls, vulnerability with the highest percentage is represented by the segment of students at risk of early school dropout, namely $66.66 \%$. The other vulnerabilities added together represent a percentage of $33.34 \%$.

In boys, there is no dominant vulnerability because the segment of students at risk of early school dropout and the segment of Roma students have equal percentages. The next vulnerability identified in boys is represented by the segment of students from disorganised or single-parent families, followed by vulnerability represented by the segment of students with one or both parents working abroad.

The comparative analysis shows a higher percentage of vulnerability for the risk of early school dropout in girls than in boys. Instead, we notice a balance between the two vulnerabilities, namely the risks of early school dropout and belonging to Roma ethnicity. (Table 3, Figure 2) 
Table 3. Overall results for the 6th grade

\begin{tabular}{lcccccc}
\hline & \multicolumn{2}{c}{ GIRLS -21} & \multicolumn{2}{c}{ BOYS - 29 } & \multicolumn{2}{c}{ TOTAL - 50 } \\
\cline { 2 - 6 } ROMA & 3 & $14.28 \%$ & 12 & $41.37 \%$ & 15 & $30.00 \%$ \\
PMS & 1 & $4.76 \%$ & 2 & $6.89 \%$ & 3 & $06.00 \%$ \\
FDM & 3 & $14.28 \%$ & 3 & $10.34 \%$ & 6 & $12.00 \%$ \\
RPTS & 14 & $66.66 \%$ & 12 & $41.37 \%$ & 26 & $52.00 \%$ \\
\hline
\end{tabular}

Legend: Roma - the student belongs to Roma ethnicity; PMS - the student has one or both parents working abroad; FDM - the student is from a disorganised or single-parent family; RPTS - the student is at risk of early school dropout for other reasons than those listed below such as belonging to a socially assisted family, cohabitation with other students exposed to the risk of early school dropout, other forms of poverty, etc.

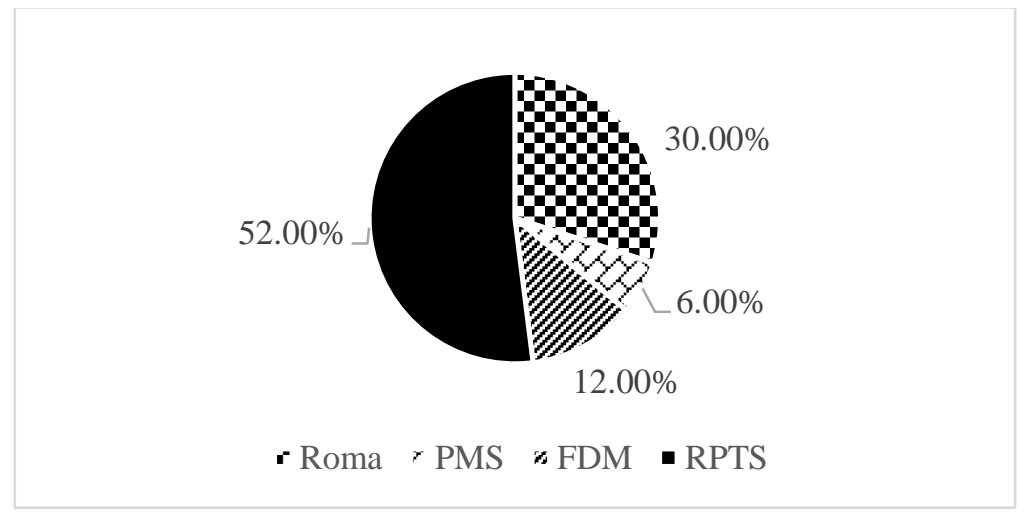

Figure 2. Structure of vulnerabilities - Overall results for the 6th grade

The processing and interpretation of data for the 7th grade show a number of 37 students at this level, of whom 17 are female (45.94\%) and 20 are male (54.05\%). Vulnerability with a major percentage is represented by the segment of students at risk of early school dropout, followed by vulnerability represented by the segment of students from disorganised or singleparent families. The next vulnerability identified in the middle-school population is represented by the segment of students with one or both parents working abroad, and the lowest percentage among vulnerabilities is represented by the segment of students of Roma ethnicity. Thus, we notice that the structure of vulnerabilities for the 7 th grade is dominated by the risk of early school dropout, namely $59.45 \%$. Regarding the structure of vulnerabilities by gender, the following differences can be observed:

In girls, vulnerability with the highest percentage is represented by the segment of students at risk of early school dropout. The second major vulnerability is represented by the segment of students of Roma ethnicity. The next two vulnerabilities identified for the female population in the 7th grade have equal percentages and are represented by the segment of students from disorganised or single-parent families and the segment of students with one or both parents working abroad.

In boys, vulnerability with the highest percentage is represented by the segment of students at risk of early school dropout. The next vulnerability identified in boys is represented by the segment of students from disorganised or single-parent families, namely $25 \%$, followed by students with one or both parents working abroad, namely $15 \%$. It is worth noting that there are no students of Roma ethnicity!

The comparative analysis shows a major percentage of vulnerability for the risk of early school dropout in both girls in boys. Instead, we notice a significant percentage of 
vulnerability for male students from disorganised or single-parent families (Table 4, Figure $3)$.

Table 4. Overall results for the 7 th grade

\begin{tabular}{|c|c|c|c|c|c|c|}
\hline \multirow[b]{2}{*}{ ROMA } & \multicolumn{2}{|c|}{ GIRLS - 17} & \multicolumn{2}{|c|}{ BOYS - 20} & \multicolumn{2}{|c|}{ TOTAL -37} \\
\hline & 3 & $17.64 \%$ & 0 & $0 \%$ & 3 & $08.10 \%$ \\
\hline PMS & 2 & $11.76 \%$ & 3 & $15.00 \%$ & 5 & $13.51 \%$ \\
\hline FDM & 2 & $11.76 \%$ & 5 & $25.00 \%$ & 7 & $18.91 \%$ \\
\hline RPTS & 10 & $58.82 \%$ & 12 & $60.00 \%$ & 22 & $59.45 \%$ \\
\hline
\end{tabular}

Legend: Roma - the student belongs to Roma ethnicity; PMS - the student has one or both parents working abroad; FDM - the student is from a disorganised or single-parent family; RPTS - the student is at risk of early school dropout for other reasons than those listed below such as belonging to a socially assisted family, cohabitation with other students exposed to the risk of early school dropout, other forms of poverty, etc.

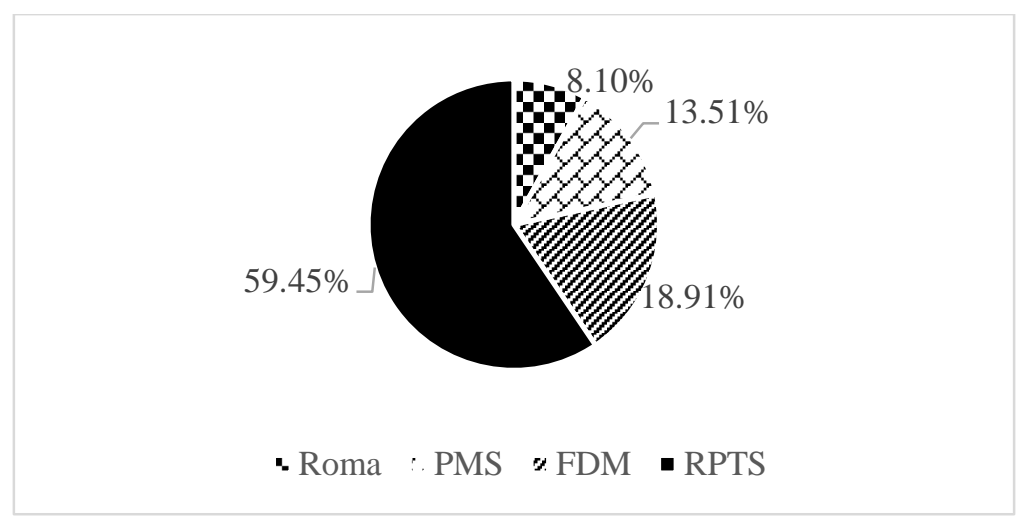

Figure 3. Structure of vulnerabilities - Overall results for the 7th grade

The processing and interpretation of data for the 8th grade shows a reversal of gender proportions, meaning that, of the 36 students, 22 are female $(61.11 \%)$ and 14 are male $(38.88 \%)$. This phenomenon is also noticed by other authors (Horga et al., 2017), who state that, in upper secondary education, there are some gender variations, the participation of girls in education being more sustained at the ages of 14 and 15. Vulnerability with the highest percentage is represented by the segment of students at risk of early school dropout. The second major vulnerability is represented by the segment of students belonging to Roma ethnicity, and the next vulnerability identified in the middle-school population is represented by the segment of students from disorganised or single-parent families. The lowest percentage among vulnerabilities is represented by the segment of students with one or both parents working abroad. Thus, we notice that the structure of vulnerabilities for the 8th grade is dominated by the risk of early school dropout. Regarding the structure of vulnerabilities by gender, a relative similarity can be observed as follows. At the same time, at the age of 14, from the perspective of gender variations in upper secondary education, there are differences between girls and boys (Horga et al., 2017).

In girls, vulnerability with the highest percentage is represented by the segment of students at risk of early school dropout, followed by vulnerability represented by the segment of students belonging to Roma ethnicity, then vulnerability represented by the segment of 
students from disorganised or single-parent families, and finally vulnerability represented by the segment of students with one or both parents working abroad.

In boys, vulnerability with the highest percentage is represented by the segment of students at risk of early school dropout, namely $50 \%$, followed by vulnerability represented by the segment of students belonging to Roma ethnicity, and then vulnerability represented by the segment of students from disorganised or single-parent families. The lowest percentage among vulnerabilities is represented by the segment of students with one or both parents working abroad, namely $7.14 \%$.

The comparative analysis shows a high percentage of vulnerability for the risk of early school dropout in both genders. A relatively similar vulnerability structure is noted in both genders (Table 5, Figure 4).

Table 5. Overall results for the 8 th grade

\begin{tabular}{lcccccc}
\hline & \multicolumn{2}{c}{ GIRLS -22} & \multicolumn{2}{c}{ BOYS - 14 } & \multicolumn{2}{c}{ TOTAL - 36 } \\
\cline { 2 - 6 } ROMA & 7 & $31.81 \%$ & 4 & $28.57 \%$ & 11 & $30.55 \%$ \\
PMS & 2 & $09.09 \%$ & 1 & $07.14 \%$ & 3 & $08.33 \%$ \\
FDM & 3 & $13.63 \%$ & 2 & $14.28 \%$ & 5 & $13.88 \%$ \\
RPTS & 10 & $45.45 \%$ & 7 & $50.00 \%$ & 17 & $47.22 \%$ \\
\hline
\end{tabular}

Legend: Roma - the student belongs to Roma ethnicity; PMS - the student has one or both parents working abroad; FDM - the student is from a disorganised or single-parent family; RPTS - the student is at risk of early school dropout for other reasons than those listed below such as belonging to a socially assisted family, cohabitation with other students exposed to the risk of early school dropout, other forms of poverty, etc.

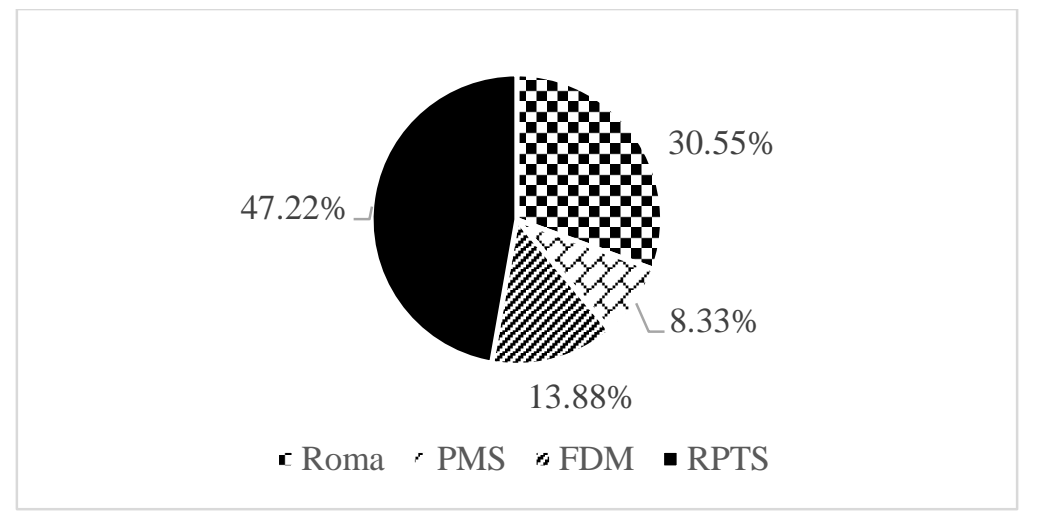

Figure 4. Structure of vulnerabilities - Overall results for the 8th grade

\section{Discussion}

As regards the structure of vulnerabilities by gender, we notice a relative similarity between the vulnerabilities of boys and girls. Also, gender structures are in accordance with the overall structure of vulnerabilities in the middle-school population. Thus, vulnerability with the highest percentage for both genders is represented by the segment of students at risk of early school dropout, but with a difference of almost 6 points in favour of girls.

The second major vulnerability for both genders is represented by the segment of students of Roma ethnicity, but with a difference of almost 8 points in favour of boys. 
The next vulnerability identified in the middle-school population is represented by the segment of students from disorganised or single-parent families, with close values for both genders.

The lowest percentage among vulnerabilities is represented by the segment of students with one or both parents working abroad, with close values for both genders.

The structure of these vulnerabilities is shown in Figures 5, 6 and 7.

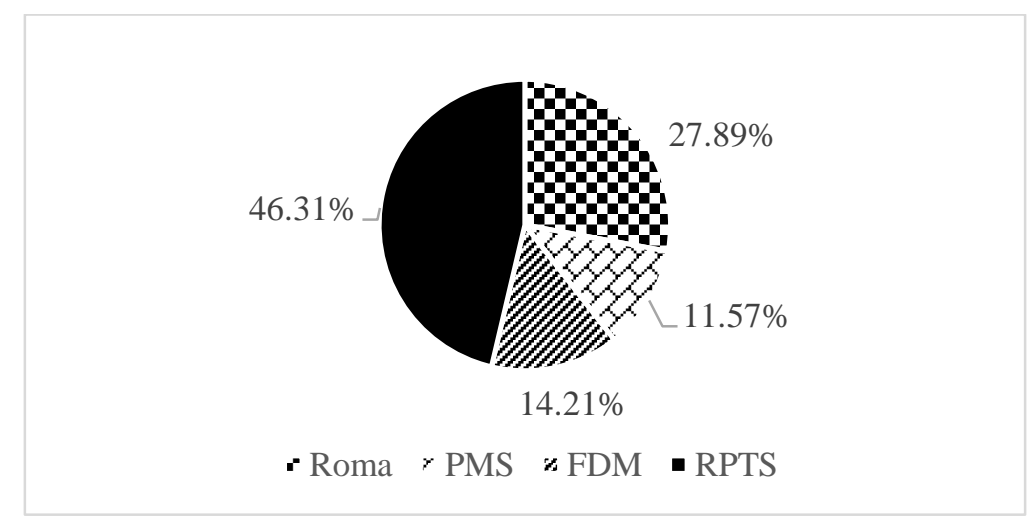

Figure 5. Structure of vulnerabilities - Overall results

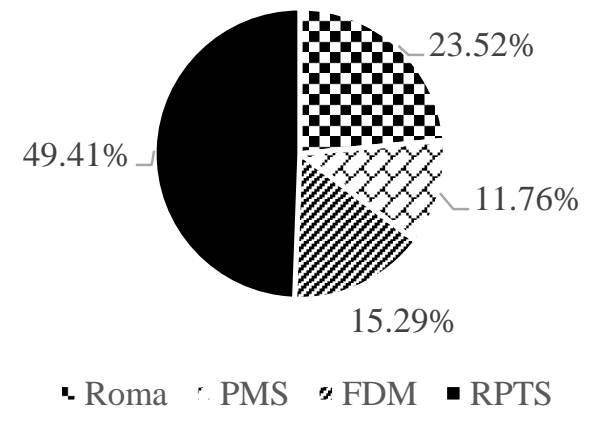

Figure 6. Structure of vulnerabilities - Girls

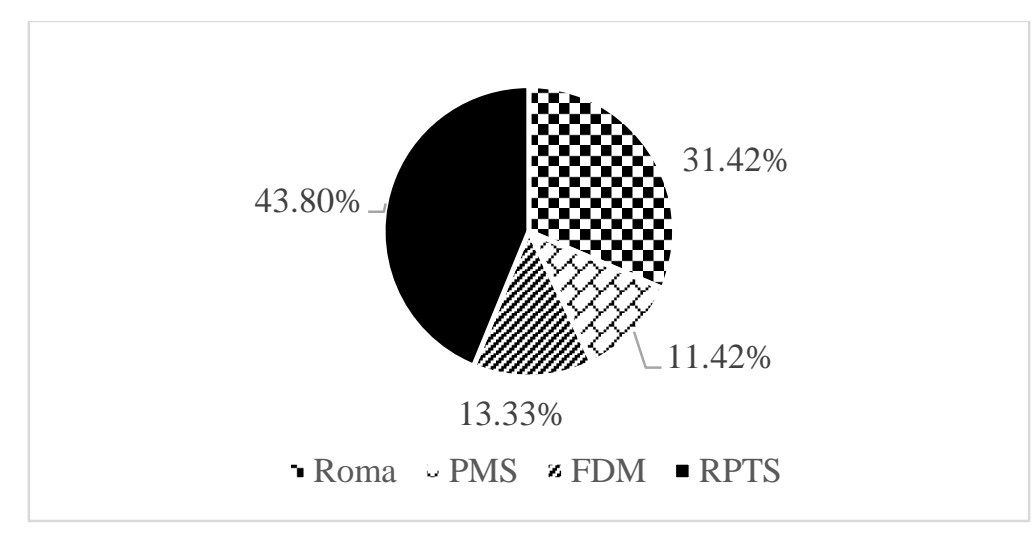

Figure 7. Structure of vulnerabilities - Boys 


\section{Conclusion}

The structure of vulnerabilities in the middle-school population is dominated by the risk of early school dropout, with a percentage of $46.31 \%$. The second major vulnerability is represented by the Roma segment of the school population, namely $27.89 \%$. The next vulnerability identified in the school population is represented by the segment of students from disorganised or single-parent families, namely $14.21 \%$. The lowest percentage among vulnerabilities is represented by the segment of students with one or both parents working abroad, namely $11.57 \%$.

If, in the 5th grade of lower secondary education, there are $37.31 \%$ female students and $62.68 \%$ male students, in the 8 th grade, there is a reversal of gender proportions, in the sense that there are $61.11 \%$ female students and $38.88 \%$ male students. This situation indicates that early school dropout during middle school is significantly higher in boys than in girls. This phenomenon has also been highlighted by other authors such as Horga et al. (2017), who claim that the gender difference in school dropout shows that more boys than girls drop out of school during high school.

At the same time, we highlight the constant erosion of most of the indicators analysed, in the context of lower secondary education, for children from families at risk of marginalisation in rural areas; thus, at the age of 14 , only $60 \%$ of rural children still attend middle school (Horga et al., 2017).

\section{Authors' Contributions}

All authors have equally contributed to this study and should be considered as main authors.

\section{References}

Baumeister, R. F., \& Leary, M. R. (1995). The need to belong: Desire for interpersonal attachments as a fundamental human motivation. Psychological Bulletin, 117(3), 497-529. https://doi.org/10.1037/0033-2909.117.3.497

Christenson, S. L., Sinclair, M. F., Lehr, C. A., \& Godber, Y. (2001). Promoting successful school completion: Critical conceptual and methodological guidelines. School Psychology Quarterly, 16(4), 468-484. https://doi.org/10.1521/scpq.16.4.468.19898

Derrington, C. (2007). Fight, flight and playing white: An examination of coping strategies adopted by Gypsy traveller adolescents in English secondary schools. International $\begin{array}{llll}\text { Journal of Educational } & \text { Research, 46(6), }\end{array}$ https://doi.org/10.1016/j.ijer.2007.06.001

Derrington, C., \& Kendall, S. (2008). Challenges and barriers to secondary education: The experiences of young Gypsy traveller students in English secondary schools. Social Policy and Society, 7(1), 119-128. https://doi.org/10.1017/S1474746407004058

Hawkley, L. C., Williams, K. D., \& Cacioppo, J. T. (2011). Responses to ostracism across adulthood. Social Cognitive and Affective Neuroscience, 6(2), 234-243. https://doi.org/10.1093/scan/nsq045 
Horga, I., Jigău, M., Apostu, O., \& Fartușnic, C. (2017). La școală. O privire asupra participării la educație folosind analiza pe cohortă [At school. A look at participation in education using cohort analysis]. București: Alpha MDN.

Ilisei, I. (2016). Cum se decide în școli egalitatea de șanse? Studiu asupra implicării părinților în procesul educațional al copiilor din categorii sociale defavorizate [How is equality of opportunity decided in schools? Study on parent involvement in the educational process of children from disadvantaged social categories]. Suceava: Mușatinii.

INS. (2017). Caiete statistice privind educația (2003-2016) [Statistical notebooks on education (2003-2016)]. Institutul Național de Statistică.

Latsch, M., \& Hannover, B. (2014). Smart girls, dumb boys!? How the discourse on "Failing Boys" impacts performances and motivational goal orientation in German school students. Social Psychology 45(2), 112-126. https://doi.org/10.1027/1864-9335/a000167

Lofstrom, M. (2007). Why are Hispanic and African-American dropout rates so high? Williams Review, 2, 91-121. https://doi.org/10.1111/j.0042-7092.2007.00700.x

Merriam-Webster Dictionary. (2020). Vulnerable. https://www.merriam-webster.com/dictionary/vulnerable

Mifsud, C., \& Rapee, R. M. (2005). Early intervention for childhood anxiety in a school setting: Outcomes for an economically disadvantaged population. Journal of the American Academy of Child \& Adolescent Psychiatry, 44(10), 996-1004. https://doi.org/10.1097/01.chi.0000173294.13441.87

Pollatos, O., Matthias, E., \& Keller, J. (2015). When interoception helps to overcome negative feelings caused by social exclusion. Frontiers in Psychology, 6: 786. https://doi.org/10.3389/fpsyg.2015.00786

Tanner-Smith, E., \& Wilson, S. J. (2013). A meta-analysis of the effects of dropout prevention programs on school absenteeism. Prevention Science, 14, 468-478. https://doi.org/10.1007/s11121-012-0330-1

Tonts, M. (2005). Competitive sport and social capital in rural Australia. Journal of Rural Studies, 21(2), 137-149. https://doi.org/10.1016/j.jrurstud.2005.03.001

Tyler, J. H., \& Lofstrom, M. (2009). Finishing high school: Alternative pathways and dropout recovery. The Future of Children, 19(1), 77-103. https://doi.org/10.1353/foc.0.0019

Wilson, S. J., Tanner-Smith, E. E., Lipsey, M. W., Steinka-Fry, K., \& Morrison, J. (2011). Dropout prevention and intervention programs: Effects on school completion and dropout among school-aged children and youth. Campbell Systematic Reviews, 8. https://doi.org/10.4073/csr.2011.8 